\title{
Kinetic Effects of Temperature on Fe-N-C Catalysts for 2e- and 4e-Oxygen Reduction Reactions
}

Jie Yang, ${ }^{1,2}$ Junfen Li, ${ }^{1,2}$ Ruimin Ding, ${ }^{1,2}$ Chang Liu,${ }^{1}$ Xi Yin ${ }^{1,2} *$

1. Institute of Coal Chemistry, Chinese Academy of Sciences, Taiyuan 030001, Shanxi, P. R. China.

2. School of Chemical Engineering, University of Chinese Academy of Sciences, Beijing 100049, P. R. China.

KEYWORDS: Fe-N-C catalysts, temperature effects, oxygen reduction reaction, hydrogen peroxide

\section{ABSTRACT}

Hydrogen peroxide $\left(\mathrm{H}_{2} \mathrm{O}_{2}\right)$ formed via the two-electron oxygen reduction reaction (2e-ORR) on Fe-N-C catalysts at elevated temperatures can cause catalyst degradation in fuel cells. In this work, we studied the effects of temperature on the selectivity of Fe$\mathrm{N}-\mathrm{C}$ catalysts for the $2 \mathrm{e}-$ and $4 \mathrm{e}-\mathrm{ORRs}$ in acidic electrolytes. The results showed that the $\mathrm{H}_{2} \mathrm{O}_{2}$ yield increased with increasing temperature, and prolonged high-temperature exposure under ORR polarization conditions led to catalyst degradation and higher 
$\mathrm{H}_{2} \mathrm{O}_{2}$ yield. These effects were further explained by means of a kinetic model describing the competitive reactions and the thermodynamics of the system.

\section{Table of Content Graphic}

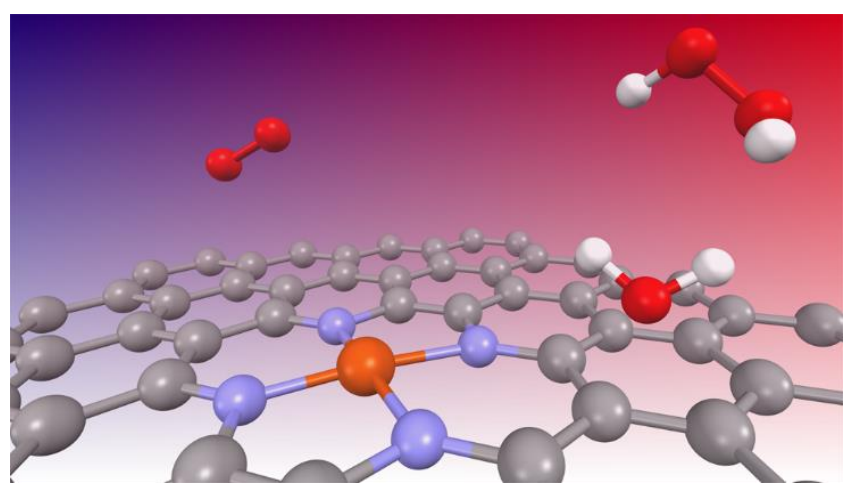

BRIEFS Kinetic analysis showed increasing selectivity for 2e-ORR and higher $\mathrm{H}_{2} \mathrm{O}_{2}$ yield on PGM-free Fe-N-C catalyst with increasing temperature.

Platinum group metal-free (PGM-free) catalysts based on iron- and nitrogen-doped carbon $(\mathrm{Fe}-\mathrm{N}-\mathrm{C})$ materials exhibit promising activity for the oxygen reduction reaction (ORR) in proton exchange membrane fuel cells (PEMFCs). ${ }^{1-6}$ Through material innovation, ${ }^{7-10}$ device engineering, $,{ }^{11}, 12$ and understanding the catalytic centers in $\mathrm{Fe}$ $\mathrm{N}-\mathrm{C}$ catalysts, ${ }^{13}, 14$ significant performance improvements were achieved in $\mathrm{H}_{2}$-air fuel cells. ${ }^{15}$ However, the lack of long-term durability of Fe-N-C catalysts in PEMFCs remains an unresolved issue in this research field. Specifically, fuel cells with PGMfree cathodes often experience a rapid loss of initial performance in the first tens to hundreds of hours, thus not satisfying the requirement for practical use. ${ }^{16,17}$

It is well known that $\mathrm{Fe}-\mathrm{N}-\mathrm{C}$ catalysts can catalyze two-electron oxygen reduction (2e-ORR, $\mathrm{O}_{2}+2 \mathrm{H}^{+}+2 \mathrm{e}^{-} \rightarrow \mathrm{H}_{2} \mathrm{O}_{2}, E^{0}=0.695 \mathrm{~V} v s$. SHE) to form hydrogen peroxide, 
as well as the subsequent hydrogen peroxide reduction reaction (HPRR, $\mathrm{H}_{2} \mathrm{O}_{2}+2 \mathrm{H}^{+}+$ $\left.2 \mathrm{e}^{-} \rightarrow 2 \mathrm{H}_{2} \mathrm{O}, E^{0}=1.78 \mathrm{~V} v s . \mathrm{SHE}\right)$, in addition to the four-electron ORR (4e-ORR, $\mathrm{O}_{2}$ $\left.+4 \mathrm{H}^{+}+4 \mathrm{e}^{-} \rightarrow 2 \mathrm{H}_{2} \mathrm{O}, E^{0}=1.23 \mathrm{~V} v s . \mathrm{SHE}\right)$. The $\mathrm{H}_{2} \mathrm{O}_{2}$ formed via the 2e-ORR pathway has been identified as a major agent leading to the fast degradation of PGM-free catalysts in fuel cells and needs to be addressed. ${ }^{18-22}$ The selectivity of Fe-N-C catalysts for the 2e-ORR at room temperature in aqueous electrolytes is often measured using a rotating ring-disk electrode (RRDE) and reported in terms of $\mathrm{H}_{2} \mathrm{O}_{2}$ yield $\left(\mathrm{Y}_{\mathrm{H} 2 \mathrm{O} 2}\right){ }^{23}$ However, this critical information at fuel cell operating temperatures (e.g., $80{ }^{\circ} \mathrm{C}$ ) is still unclear, as there has been limited research on the dependence of $\mathrm{H}_{2} \mathrm{O}_{2}$ yield on temperature. ${ }^{24-26}$ It is important to study the temperature effects on $Y_{\mathrm{H} 2 \mathrm{O} 2}$ and report the values at elevated temperatures, as this information is essential to the understanding of catalyst degradation during fuel cell operations. In addition, since Fe-N-C catalysts degrade rapidly in fuel cells, the effects of catalyst degradation during experiments should be carefully evaluated and differentiated with the intrinsic temperature dependence. ${ }^{24-26}$

In this work, we examined the effects of temperature on the selectivity of Fe-N-C catalysts for the $2 \mathrm{e}$ - and $4 \mathrm{e}-\mathrm{ORRs}$ between 25 and $80{ }^{\circ} \mathrm{C}$ in an aqueous acidic electrolyte using a high-temperature rotating ring-disk electrode (HT-RRDE). The variation of $Y_{\mathrm{H} 2 \mathrm{O} 2}$ with temperature was quantitatively analyzed with a kinetic model and linked to the thermodynamics of the system. ${ }^{27,28}$ In addition, control experiments were carried out to quantify the effects of prolonged high-temperature exposure on the selectivity of the Fe-N-C catalyst. Our results showed that $Y_{\mathrm{H} 2 \mathrm{O} 2}$ is related not only to the electrolyte 
temperature but also to the history of high-temperature exposure of the electrode. These findings will help us understand the degradation behavior of PGM-free catalysts in fuel cell systems at elevated temperatures.

The Fe-N-C catalyst used in this work was synthesized by pyrolyzing a precursor mixture containing iron chloride $\left(\mathrm{FeCl}_{3}\right)$, poly-2-aminobenzylamine, and oxidized carbon black using a previously published method. ${ }^{29}$ Structural analysis shows that this catalyst mainly contains atomically dispersed iron atoms on graphene-like nitrogendoped carbon structures (see the Supporting Information for details, Figure S1-S4). Its physical characteristics agree with our previous report.

The effects of temperature on the Fe-N-C catalyst's selectivity for the $2 \mathrm{e}$ - and $4 \mathrm{e}-$ ORRs were carefully studied using a set of individual heating experiments. Specifically, electrodes \#1, \#2, and \#3 loaded with the Fe-N-C catalyst were first tested at $25{ }^{\circ} \mathrm{C}$ to ensure consistent activity and selectivity (Figure S5; see the Supporting Information for details). Then, these three electrodes were immediately tested at 40, 60, and $80{ }^{\circ} \mathrm{C}$. This experimental design can minimize the effects of the history of hightemperature exposure on the catalyst, which will be discussed later in this work.

Figure 1a compares the ORR polarization curves measured at $25,40,60$ and $80{ }^{\circ} \mathrm{C}$. The onset potential ( $\left.E_{\text {onset }}\right)$ for the ORR remains constant at $c a .0 .88 \mathrm{~V} v s$. RHE from 25 to $80{ }^{\circ} \mathrm{C}$. The limiting current density $\left(j_{\mathrm{d}}\right)$ increased when the solution temperature increased from 25 to $40{ }^{\circ} \mathrm{C}\left(\mathrm{ca} .3 .43 \mathrm{~mA} / \mathrm{cm}^{2}\right)$ and then decreased when the temperature further increased to $80{ }^{\circ} \mathrm{C}\left(c a .2 .44 \mathrm{~mA} / \mathrm{cm}^{2}\right)$. A similar effect of temperature on $j_{\mathrm{d}}$ was observed for the $\mathrm{Pt} / \mathrm{C}$ catalyst in $0.5 \mathrm{M} \mathrm{H}_{2} \mathrm{SO}_{4}$, which can be attributed to the 
temperature dependence of several parameters, including the concentration and diffusion coefficient of oxygen in the electrolyte solution, the kinetic viscosity, and the number of electrons transferred. ${ }^{30}$ Figure $1 \mathrm{~b}$ shows the cyclic voltammograms (CV) measured at various temperatures. A pair of broad faradaic peaks centered at $c a .0 .6 \mathrm{~V}$ appeared and increased in intensity when the temperature increased from 25 to $80{ }^{\circ} \mathrm{C}$. These peaks are attributed to the redox of oxygen-containing groups on the $\mathrm{Fe}-\mathrm{N}-\mathrm{C}$ catalyst surface, such as the quinone/hydroquinone redox pair. ${ }^{31,32}$ The increase in the intensity of these redox peaks with temperature suggests that catalyst oxidation was accelerated at elevated temperature, and the formation of oxygen-containing groups led to an increase in the pseudocapacitance. ${ }^{33}$ Figures $1 \mathrm{c}$ and $1 \mathrm{~d}$ show the measured $Y_{\mathrm{H} 2 \mathrm{O} 2}$ values at various temperatures. With an increase in temperature from 25 to $80^{\circ} \mathrm{C}$, the $Y_{\mathrm{H} 2 \mathrm{O} 2}$ at $0 \mathrm{~V}$ increased from $c a .2 \%$ to $5 \%$, corresponding to a percentage increase of $200 \%$. These results suggested that the apparent $\mathrm{H}_{2} \mathrm{O}_{2}$ yield increased slightly when the cell temperature increased from 25 to $80{ }^{\circ} \mathrm{C}$. 

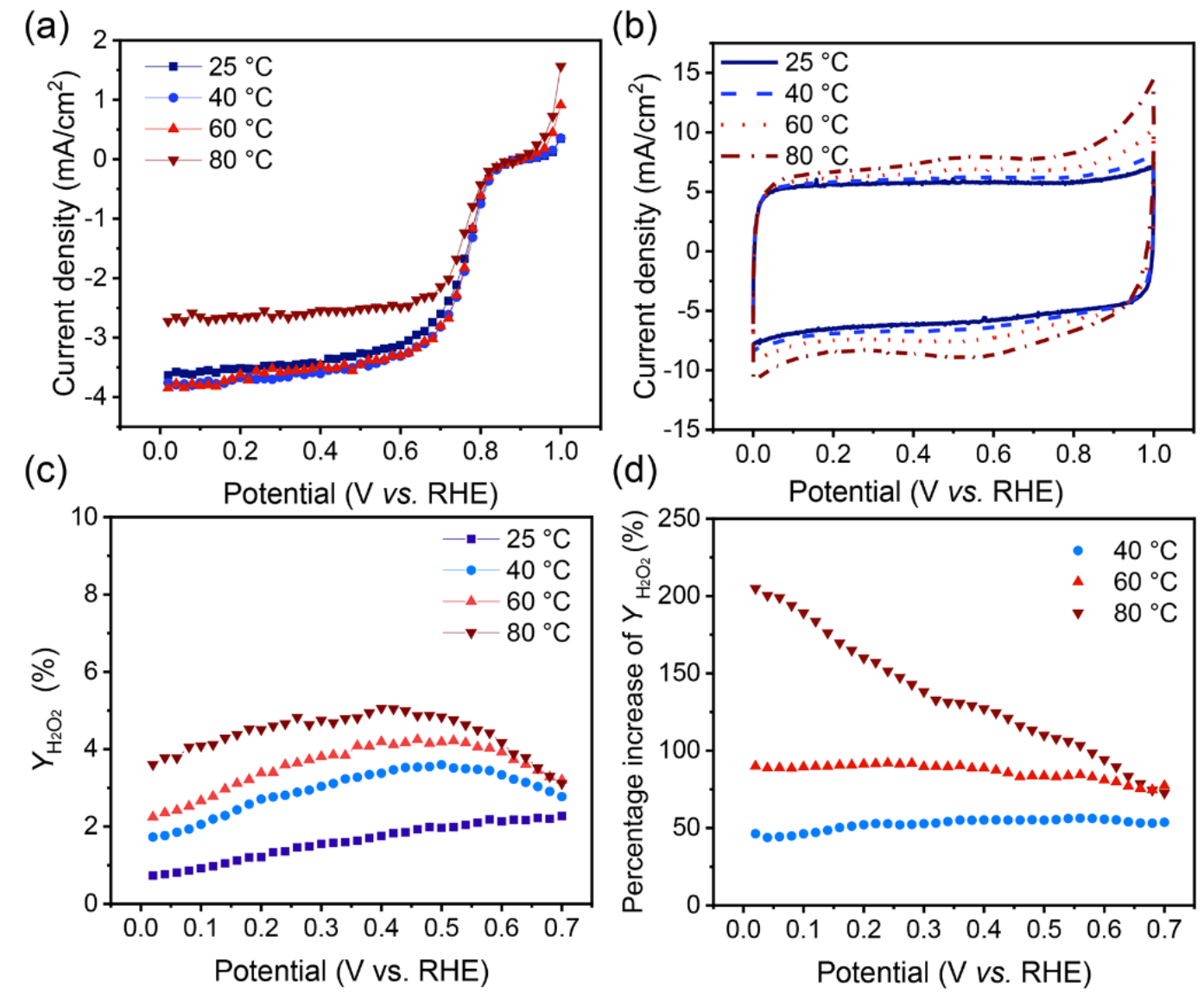

Figure 1. Results of the individual heating experiments: (a) Steady-state ORR polarization curves, (b) cyclic voltammograms, and (c) $\mathrm{H}_{2} \mathrm{O}_{2}$ yields of individual Fe$\mathrm{N}-\mathrm{C}$ electrodes in $0.5 \mathrm{M} \mathrm{H}_{2} \mathrm{SO}_{4}$ at various temperatures. (d) Percentage increase of $Y_{\mathrm{H} 2 \mathrm{O} 2}$ with temperature.

We used Tafel analysis to gain kinetic insight into the temperature dependence of the catalytic selectivity for the ORRs. At a large overpotential, the current can be described using the Tafel approximation of the Bulter-Volmer equation: ${ }^{34}$

$$
j_{k}=j_{0} e^{-\frac{\alpha F}{R T} \eta}
$$

where $j_{\mathrm{k}}$ is the kinetically limited current, $j_{0}$ is the exchange current density, $\alpha$ is the transfer coefficient, $F$ is the Faraday constant, $R$ is the ideal gas constant, $T$ is the 
absolute temperature, and $\eta$ is the overpotential. Here, $\eta$ is the difference between the applied potential and the thermodynamic equilibrium potential $\left(E_{T}\right)$. Based on the previously reported thermodynamic data of the related chemical species, $E_{T}(2 \mathrm{e}-\mathrm{ORR})$ and $E_{T}(4 \mathrm{e}-\mathrm{ORR})$ both decrease with increasing temperature but at different rates, as shown in Figure 2a. The temperature coefficients $(\mathrm{d} E / \mathrm{d} T)$ of $E_{T}(2 \mathrm{e}-\mathrm{ORR})$ and $E_{T}(4 \mathrm{e}-\mathrm{ORR})$ are $c a .-0.993$ and $-0.846 \mathrm{mV} /{ }^{\circ} \mathrm{C}$, respectively, between 25 and $100{ }^{\circ} \mathrm{C} .{ }^{35}$ With the difference in temperature coefficients, $E_{T}(2 \mathrm{e}-\mathrm{ORR})$ and $E_{T}(4 \mathrm{e}-\mathrm{ORR})$ will shift for different values and affect the overpotential $(\eta)$ for these reactions when the electrode potential is controlled with reference to RHE.

By correcting the above effects and applying the Koutecký-Levich equation, we obtained the Tafel plot of $j_{\mathrm{k}}$ for $4 \mathrm{e}-\mathrm{ORR}$ at various temperatures, as shown in Figure $2 \mathrm{~b}$. With increasing temperature, the Tafel slope $(b)$ of the linear regions remained ca. $-60 \mathrm{mV} \mathrm{dec}{ }^{-1}$ (Figure 2c). Since $b=-2.303 R T /(\alpha F)$ for the rate-determining step (RDS) of the one-electron reaction, the nearly unchanged $b$ implies that $\alpha$ and $T$ changed proportionally to each other. 

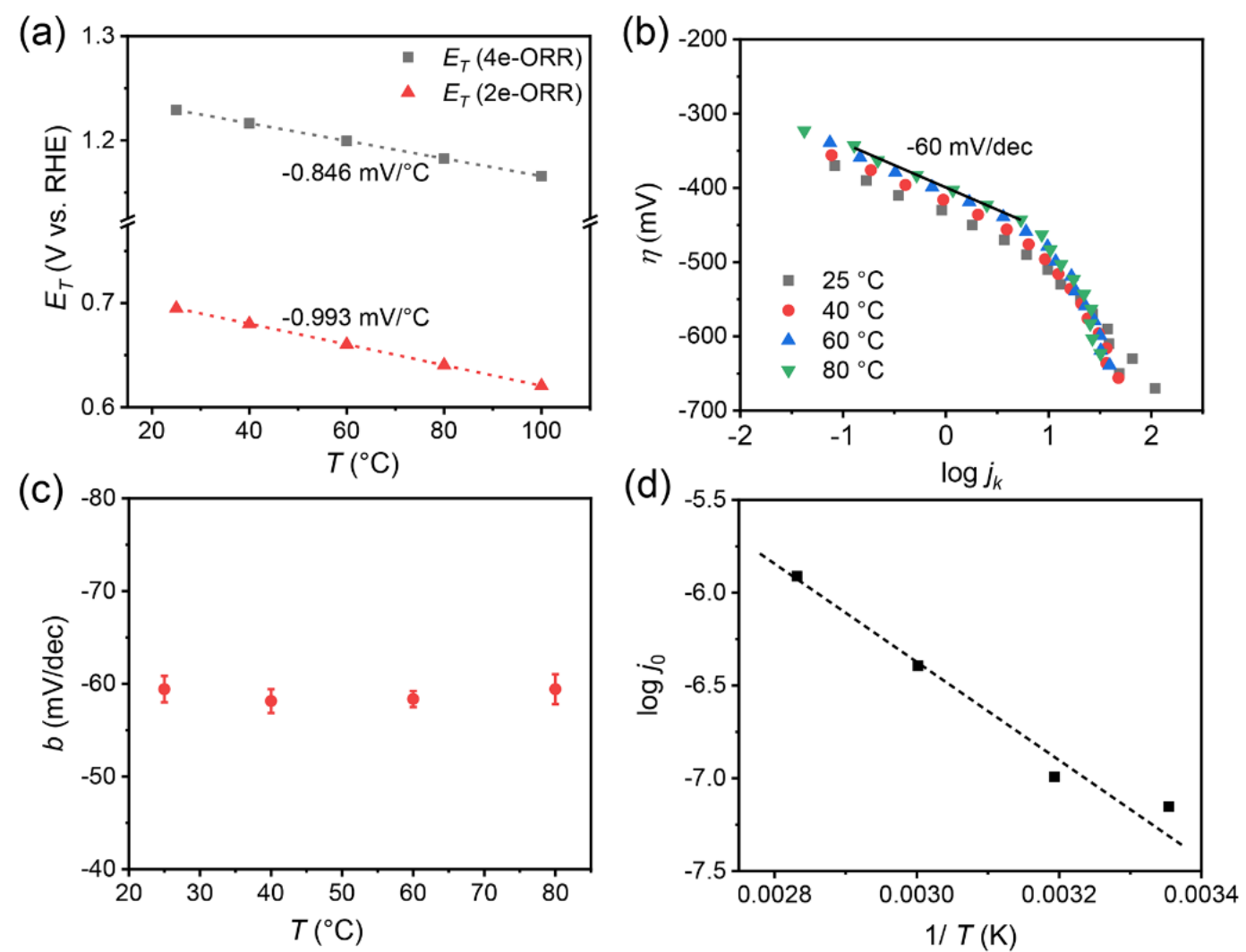

Figure 2. (a) Temperature dependence of the thermodynamic equilibrium potential $\left(E_{T}\right)$ for the $4 \mathrm{e}$ - and $2 \mathrm{e}-\mathrm{ORR}$ calculated from the experimental thermodynamic data. ${ }^{35}$ (b) Tafel plot of the kinetically limited current $\left(j_{\mathrm{k}}\right)$ for the ORR measured at various temperatures. The overpotential $(\eta)$ was calculated based on the $E_{T}$ at various temperatures. (c) Change in the Tafel slope $b$ with temperature. (d) The exchange current density $\left(j_{0}\right)$ versus $1 / T$.

The exchange current density ( $\left.j_{0}\right)$ obtained by extrapolating the linear region to zero overpotential increased with temperature, suggesting that the turnover frequency for the $4 \mathrm{e}-\mathrm{ORR}$ at the catalytic center increased with temperature assuming the number of 
active sites remained the same. Figure $2 \mathrm{~d}$ shows the plot of $\log j_{0}$ versus $1 / T$. Based on the Erying equation, $\log j_{0}$ can be expressed as

$$
\mathrm{d}\left(\log j_{0}\right) / \mathrm{d}(\log 1 / T)=-\Delta H^{\ddagger} / 2.303 R
$$

where $\Delta H^{\ddagger}$ is the activation enthalpy for the rate-determining step (see the Supporting Information for detail). We determined that for the 4e-ORR catalyzed by the Fe-N-C catalyst, $\Delta H^{\ddagger}$ is $52 \pm 6 \mathrm{~kJ} / \mathrm{mol}$, close to the value reported in literature. ${ }^{36}$

We further applied a method developed by Hsueh et al. ${ }^{37}$ to quantitatively analyze the temperature dependence of the 2e- and 4e-ORR kinetics (see the Supporting Information for detail). This method was based on a model proposed by Damjanovic et al. ${ }^{38}$ The model describes the system with three electrochemical reactions (4e-ORR, 2e-ORR and HPRR) and the desorption/adsorption reaction of $\mathrm{H}_{2} \mathrm{O}_{2}$ (Figure 3a). It is assumed that there is no catalytic decomposition of $\mathrm{H}_{2} \mathrm{O}_{2}$, the adsorption and desorption of $\mathrm{H}_{2} \mathrm{O}_{2}$ are fast and in equilibrium, and the electrochemical oxidation of $\mathrm{H}_{2} \mathrm{O}_{2}$ is negligible below $0.8 \mathrm{~V} v s$. RHE. By analyzing RRDE experiments at various rotation rates at a certain temperature (Figure S6 and Table S1-S2, see Supporting Information for details), the rate constants of the $4 \mathrm{e}-\mathrm{ORR}, 2 \mathrm{e}-\mathrm{ORR}$ and HPRR, denoted as $k_{1}, k_{2}$, and $k_{3}$, respectively, can be obtained. Figure $3 \mathrm{~b}$ shows the $k$ values measured at 25 and $80{ }^{\circ} \mathrm{C}$. When the temperature increased from 25 to $80{ }^{\circ} \mathrm{C}$, the rate constants over the entire potential range all increased. We quantified the increase in the rate constant with temperature by defining a temperature coefficient, $\gamma$, where $\gamma\left(k_{i}\right)=\log \left[k_{i}\left(80{ }^{\circ} \mathrm{C}\right) / k_{i}\left(25{ }^{\circ} \mathrm{C}\right)\right] / \Delta T$. Figure $3 \mathrm{c}$ shows that $\gamma\left(k_{1}\right)<\gamma\left(k_{2}\right) \approx \gamma\left(k_{3}\right)$, suggesting that the 2e-ORR and HPRR accelerated more significantly than the 4e-ORR 
in response to increasing temperature. Considering the above findings, we expect that the $Y_{\mathrm{H} 2 \mathrm{O} 2}$ in PGM-free PEMFC cathodes may also increase with the cell temperature. The formation rate of $\mathrm{H}_{2} \mathrm{O}_{2}$ could be higher than that projected based on roomtemperature data and may impact the fuel cell stability more negatively than previously expected.

(a)

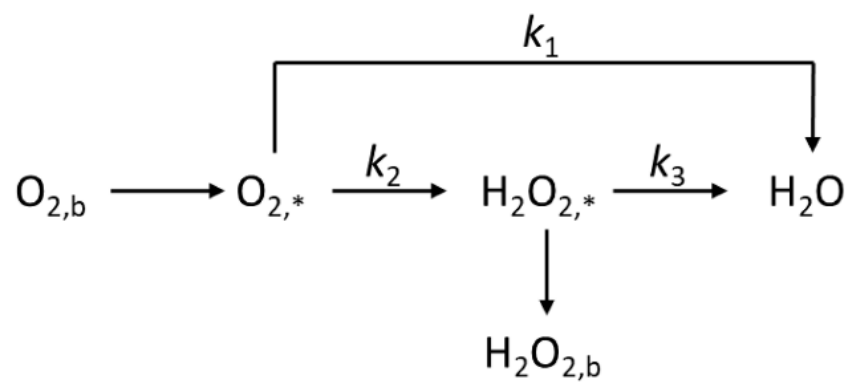

(b)

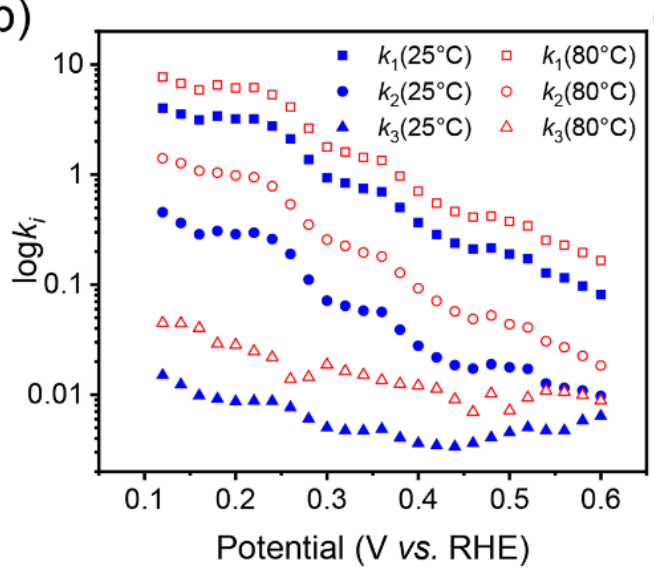

(c)

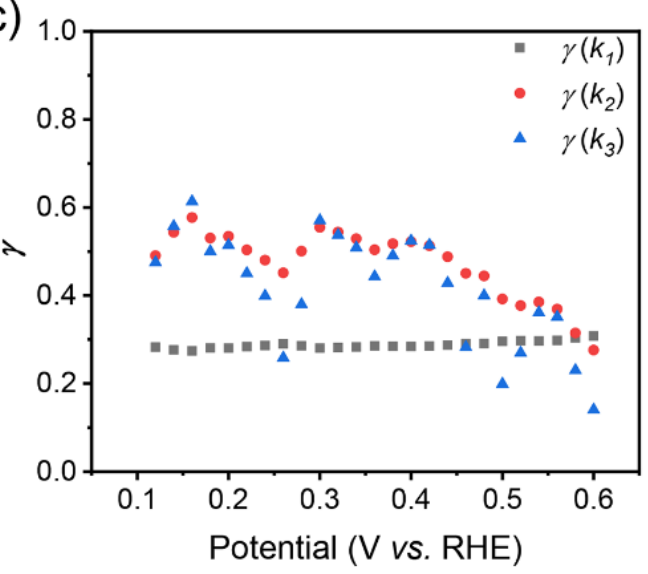

Figure 3. (a) Kinetic model for ORR proposed by Damjanovic et al. ${ }^{38}$ Symbol b and $*$ represent species in bulk solution and adsorbed state, respectively. (b) Rate constants $k_{1}, k_{2}$ and $k_{3}$ as a function of potential at 25 and $80^{\circ} \mathrm{C}$. (c) Temperature coefficients $\gamma\left(k_{1}\right)$, $\gamma\left(k_{2}\right)$, and $\gamma\left(k_{3}\right)$ compared at different potentials. 
In addition to the above findings, we also noted that prolonged temperature exposure in an electrolyte solution can lead to an increase in $Y_{\mathrm{H} 2 \mathrm{O} 2}$, most likely due to irreversible catalyst degradation. Figure S7 shows the results of the sequential heating experiment, in which one electrode was tested sequentially at $25,40,60$, and $80{ }^{\circ} \mathrm{C}$ when the solution was heated over approximately 3.5 hours. The $Y_{\mathrm{H} 2 \mathrm{O} 2}$ value increased from $c a .2 .00 \%$ to $7.00 \%$ (Figure S7c). However, the percentage increase in $Y_{\mathrm{H} 2 \mathrm{O} 2}$ at $0 \mathrm{~V}$ was up to $c a$. $280 \%$, higher than that observed during the individual heating experiments (ca. 200\%) (Figure S7d). This difference could be due to the catalyst degradation occurred during the prolonged heating process. During a sequential cooling experiment (Figure 4), the electrochemical data for one electrode were recorded while the solution was first heated to $80{ }^{\circ} \mathrm{C}$ in one hour and then cooled to $25^{\circ} \mathrm{C}$ in five hours. The $Y_{\mathrm{H} 2 \mathrm{O} 2}$ value at $0 \mathrm{~V}$ increased from $c a .2 \%$ to $7 \%$ when the cell temperature increased to $80{ }^{\circ} \mathrm{C}$, and then further increased to $c a .11 \%$ (Fig. 4a-b) when the cell was cooled from 80 to $25{ }^{\circ} \mathrm{C}$, corresponding to a percentage increase of $570 \%$. The catalyst showed an irreversible increase in $Y_{\mathrm{H} 2 \mathrm{O} 2}$ and a decrease in $E_{1 / 2}$ in comparison to its initial state at $25{ }^{\circ} \mathrm{C}$. These irreversible changes were accompanied by the permanent appearance of redox peaks centered at $c a .0 .6 \mathrm{~V}$ in the $\mathrm{CV}$ curves (Figure 4c), which are associated with the formation of oxygen-containing groups. ${ }^{31,32}$ Based on these results, we propose that catalyst degradation occurring at the ORR potential during prolonged heating/cooling experiments may also lead to an increase in $Y_{\mathrm{H} 2 \mathrm{O} 2}$ and a loss of activity. It is expected that the slow start-up and heating of PEMFCs with the presence of oxygen in PGM-free cathode may lead to an irreversible loss of catalyst activity and a 
significant increase in $Y_{\mathrm{H} 2 \mathrm{O} 2}$, decreasing the stability of the system. By shortening the break-in time of PGM-free cathodes in fuel cells research, a higher initial fuel cell performance is expected, as observed in recent report. ${ }^{39}$

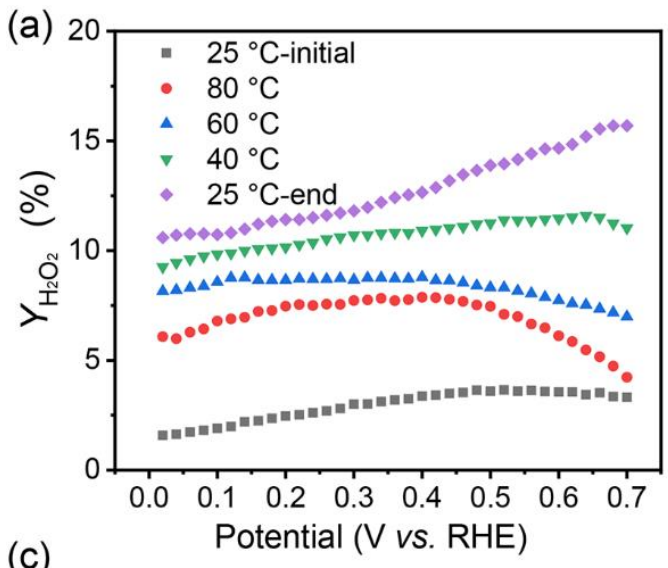

(c)
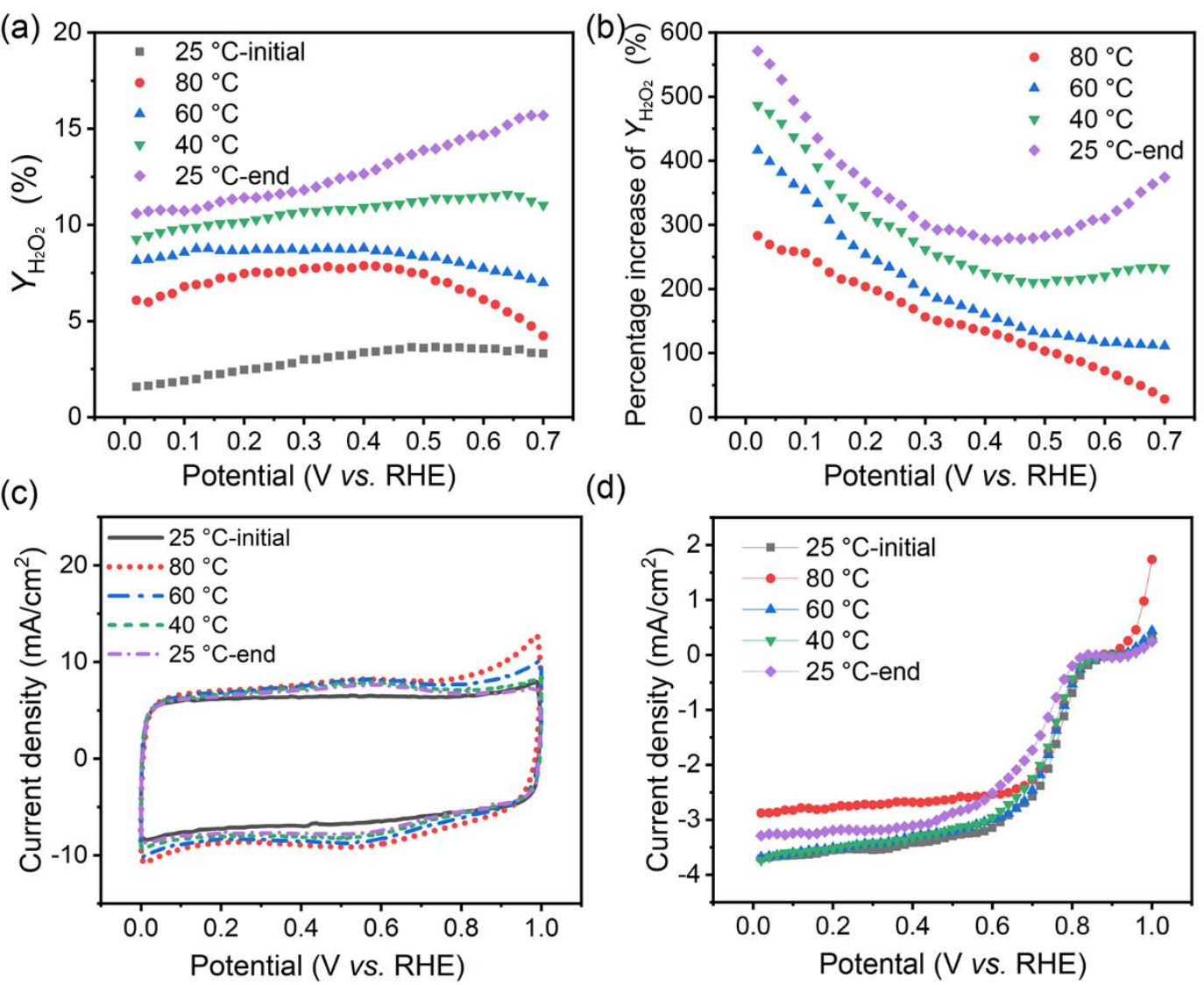

Figure 4. Results of a sequential cooling experiment for a single electrode loaded with

Fe-N-C catalyst: (a) $\mathrm{H}_{2} \mathrm{O}_{2}$ yields, (b) the percentage increase of $Y_{\mathrm{H} 2 \mathrm{O} 2}$, (c) cyclic voltammograms, and (d) steady-state ORR polarization curves measured in $0.5 \mathrm{M}$ $\mathrm{H}_{2} \mathrm{SO}_{4}$.

In summary, we studied the effects of temperature on the selectivity of Fe-N-C catalysts for the 2e- and 4e-ORRs in an aqueous acidic electrolyte between 25 and $80{ }^{\circ} \mathrm{C}$. We quantified the increase in $Y_{\mathrm{H} 2 \mathrm{O} 2}$ with temperature and attributed this finding 
to the temperature dependence of $2 \mathrm{e}$ - and $4 \mathrm{e}-\mathrm{ORR}$ thermodynamics and reaction kinetics. With increasing temperature, the thermodynamic overpotentials for these two competing reactions shift differently. The exchange current density at zero overpotential also increased with temperature. By fitting the linear relationship between $j_{0}$ and $1 / T$, the activation enthalpy of RDS for the 4e-ORR catalyzed by the Fe-N-C catalyst was determined to be $52 \pm 6 \mathrm{~kJ} / \mathrm{mol}$. Kinetic analysis showed that the temperature coefficient for the 2e-ORR was the highest for all competing reactions. As a result, the selectivity toward the 2e-ORR increased with increasing temperature. In addition, prolonged high-temperature exposure of the catalyst at ORR polarization potentials can result in an irreversible increase in $Y_{\mathrm{H} 2 \mathrm{O} 2}$ and should be differentiated from the above kinetic effects. These results imply that the formation of $\mathrm{H}_{2} \mathrm{O}_{2}$ could be a much more severe problem in fuel cells at $80{ }^{\circ} \mathrm{C}$ than predicted based on roomtemperature selectivity data. Prolonged exposure of the PGM-free cathode to a high cell temperature and ORR potential may lead to an irreversible increase in $\mathrm{H}_{2} \mathrm{O}_{2}$ yield and loss of activity due to catalyst degradation.

\section{ASSOCIATED CONTENT}

Supporting Information. The Supporting Information is available free of charge. Additional physical/electrochemical characterization data, XPS spectra, XRD patterns and SEM micrographs (PDF). 


\section{AUTHOR INFORMATION}

\section{Corresponding Author}

*Prof. Xi Yin, Email: xiyin@ sxicc.ac.cn

\section{Author Contributions}

The manuscript was written through contributions of all authors. All authors have given approval to the final version of the manuscript.

\section{Funding Sources}

Start-up fund from the Institute of Coal Chemistry, Chinese Academy of Science.

\section{Notes}

There is no conflict of interest.

\section{ACKNOWLEDGMENT}

Financial support from the Institute of Coal Chemistry, Chinese Academy of

Science is greatly acknowledged.

\section{ABBREVIATIONS}

PGM-free, platinum group metal-free; Fe-N-C, iron- and nitrogen-doped carbon;

ORR, oxygen reduction reaction; PEMFC, proton exchange membrane fuel cells;

HPRR, hydrogen peroxide reduction reaction; RRDE, rotating ring-disk electrode;

HT-RRDE, high-temperature rotating ring-disk electrode; CV, cyclic voltammogram;

RHE, reversible hydrogen electrode; RDS, rate-determining step. 


\section{REFERENCES}

1. Martinez, U.; Babu, S. K.; Holby, E. F.; Chung, H. T.; Yin, X.; Zelenay, P. Progress in the Development of Fe-Based PGM-Free Electrocatalysts for the Oxygen Reduction Reaction. Adv. Mater. 2019, 31, 1806545.

2. Shao, M. H.; Chang, Q. W.; Dodelet, J. P.; Chenitz, R. Recent Advances in Electrocatalysts for Oxygen Reduction Reaction. Chem. Rev. 2016, 2, 3594-3657.

3. Gewirth, A. A.; Varnell, J. A.; DiAscro, A. M. Nonprecious Metal Catalysts for Oxygen Reduction in Heterogeneous Aqueous Systems. Chem. Rev. 2018, 3, 23132339.

4. Barkholtz, H. M.; Liu, D. J. Advancements in Rationally Designed PGM-Free Fuel Cell Catalysts Derived from Metal-Organic Frameworks. Mater. Horizons 2017, 4, 20-37.

5. Zhang, H. G.; Osgood, H.; Xie, X. H.; Shao, Y. Y.; Wu, G. Engineering Nanostructures of PGM-Free Oxygen-Reduction Catalysts Using Metal-Organic Frameworks. Nano Energy 2017, 31, 331-350.

6. Wang, W.; Jia, Q.; Mukerjee, S.; Chen, S. Recent Insights into the OxygenReduction Electrocatalysis of Fe/N/C Materials. ACS Catal. 2019, 9, 10126-10141.

7. Wu, G.; More, K. L.; Johnston, C. M.; Zelenay, P. High-Performance Electrocatalysts for Oxygen Reduction Derived from Polyaniline, Iron, and Cobalt. Science 2011, 332, 443-447.

8. Lefèvre, M.; Proietti, E.; Jaouen, F.; Dodelet, J.-P. Iron-Based Catalysts with 
Improved Oxygen Reduction Activity in Polymer Electrolyte Fuel Cells. Science 2009, 324, 71-74.

9. Wang, Y.-C.; Lai, Y.-J.; Song, L.; Zhou, Z.-Y.; Liu, J.-G.; Wang, Q.; Yang, X.-D.; Chen, C.; Shi, W.; Zheng, Y.-P.; Rauf, M.; Sun, S.-G. S-Doping of an Fe/N/C ORR Catalyst for Polymer Electrolyte Membrane Fuel Cells with High Power Density. Angew. Chem. Int. Ed. 2015, 54, 9907-9910.

10. Wang, M.-Q.; Yang, W.-H.; Wang, H.-H.; Chen, C.; Zhou, Z.-Y.; Sun, S.-G. Pyrolyzed Fe-N-C Composite as an Efficient Non-Precious Metal Catalyst for Oxygen Reduction Reaction in Acidic Medium. ACS Catal. 2014, 4, 3928-3936.

11. Yin, X.; Lin, L.; Chung, H. T.; Babu, S. K.; Martinez, U.; Purdy, G. M.; Zelenay, P. Effects of MEA Fabrication and Ionomer Composition on Fuel Cell Performance of PGM-free ORR Catalyst. ECS Trans. 2017, 77, 1273-1281.

12. Banham, D.; Kishimoto, T.; Zhou, Y.; Sato, T.; Bai, K.; Ozaki, J.-I.; Imashiro, Y.; Ye, S. Critical Advancements in Achieving High Power and Stable Nonprecious Metal Catalyst-Based MEAs for Real-World Proton Exchange Membrane Fuel Cell Applications. Sci. Adv. 2018, 4, eaar7180.

13. Matanovic, I.; Artyushkova, K.; Atanassov, P. Understanding PGM-Free Catalysts by Linking Density Functional Theory Calculations and Structural Analysis: Perspectives and Challenges. Curr. Opin. Electrochem. 2018, 9, 137-144.

14. Xiao, M.; Zhu, J.; Ma, L.; Jin, Z.; Ge, J.; Deng, X.; Hou, Y.; He, Q.; Li, J.; Jia, Q.; Mukerjee, S.; Yang, R.; Jiang, Z.; Su, D.; Liu, C.; Xing, W. Microporous Framework Induced Synthesis of Single-Atom Dispersed Fe-N-C Acidic ORR 
Catalyst and Its in Situ Reduced Fe-N 4 Active Site Identification Revealed by XRay Absorption Spectroscopy. ACS Catal. 2018, 8, 2824-2832.

15. Qiao, M.; Wang, Y.; Wang, Q.; Hu, G.; Mamat, X.; Zhang, S.; Wang, S. Hierarchically Ordered Porous Carbon with Atomically Dispersed $\mathrm{FeN}_{4}$ for Ultraefficient Oxygen Reduction Reaction in Proton-Exchange Membrane Fuel Cells. Angew. Chem. Int. Ed. 2020, 59, 2688-2694.

16. Proietti, E.; Jaouen, F.; Lefèvre, M.; Larouche, N.; Tian, J.; Herranz, J.; Dodelet, J.-P. Iron-Based Cathode Catalyst with Enhanced Power Density in Polymer Electrolyte Membrane Fuel Cells. Nat. Commun. 2011, 2, 416.

17. Banham, D.; Ye, S.; Pei, K.; Ozaki, J.-I.; Kishimoto, T.; Imashiro, Y. A Review of the Stability and Durability of Non-Precious Metal Catalysts for the Oxygen Reduction Reaction in Proton Exchange Membrane Fuel Cells. J. Power Sources $\mathbf{2 0 1 5}, 285,334-348$.

18. Goellner, V.; Armel, V.; Zitolo, A.; Fonda, E.; Jaouen, F. Degradation by Hydrogen Peroxide of Metal-Nitrogen-Carbon Catalysts for Oxygen Reduction. $J$. Electrochem. Soc. 2015, 15, H403-H414.

19. Kramm, U. I.; Lefèvre, M.; Bogdanoff, P.; Schmeisser, D.; Dodelet, J. P. Analyzing Structural Changes of Fe-N-C Cathode Catalysts in PEM Fuel Cell by Mössbauer Spectroscopy of Complete Membrane Electrode Assemblies. J. Phys. Chem. Lett. 2014, 17, 3750-3756.

20. Goellner, V.; Baldizzone, C.; Schuppert, A.; Sougrati, M. T.; Mayrhofer, K.; Jaouen, F. Degradation of Fe/N/C Catalysts Upon High Polarization in Acid Medium. Phys. 
Chem. Chem. Phys. 2014, 18, 18454-18462.

21. Bae, G.; Chung, M. W.; Ji, S. G.; Jaouen, F.; Choi, C. H. pH Effect on the $\mathrm{H}_{2} \mathrm{O}_{2}-$ Induced Deactivation of Fe-N-C Catalysts. ACS Catal. 2020, 10, 8485-8495.

22. Holby, E. F.; Wang, G.; Zelenay, P. Acid Stability and Demetalation of PGM-Free ORR Electrocatalyst Structures from Density Functional Theory: A Model for “Single-Atom Catalyst” Dissolution. ACS Catal. 2020, 10, 14527-14539.

23. Zhang, G. X.; Wei, Q. L.; Yang, X. H.; Tavares, A. C.; Sun, S. H. RRDE Experiments on Noble-Metal and Noble-Metal-Free Catalysts: Impact of Loading on the Activity and Selectivity of Oxygen Reduction Reaction in Alkaline Solution. Appl. Catal. B-Environ. 2017, 20, 115-126.

24. Choi, C. H.; Lim, H. K.; Chung, M. W.; Chon, G.; Sahraie, N. R.; Altin, A.; Sougrati, M. T.; Stievano, L.; Oh, H. S.; Park, E. S.; Luo, F.; Strasser, P.; Drazic, G.; Mayrhofer, K. J. J.; Kim, H.; Jaouen, F. The Achilles' Heel of Iron-based Catalysts during Oxygen Reduction in an Acidic Medium. Energy Environ. Sci. 2018, 21, 3176-3182.

25. Choi, C. H.; Baldizzone, C.; Grote, J. P.; Schuppert, A. K.; Jaouen, F.; Mayrhofer, K. J. J. Stability of Fe-N-C Catalysts in Acidic Medium Studied by Operando Spectroscopy. Angew. Chem. Int. Ed. 2015, 19, 12753-12757.

26. Zhu, Z. Y.; Liu, Q. T.; Liu, X. F.; Shui, J. L. Temperature Impacts on Oxygen Reduction Reaction Measured by the Rotating Disk Electrode Technique. J. Phys. Chem. C 2020, 124, 3069-3079.

27. Muthukrishnan, A.; Nabae, Y.; Okajima, T.; Ohsaka, T. Kinetic Approach to 
Investigate the Mechanistic Pathways of Oxygen Reduction Reaction on FeContaining N-Doped Carbon Catalysts. ACS Catal. 2015, 5, 5194-5202.

28. Wu, J.; Nabae, Y.; Muthukrishnan, A.; Ohsaka, T. Electrochemical Deposition and Dissolution of Fe Species for N-doped Carbon to Understand the Degradation Mechanism of Pt-free Oxygen Reduction Catalysts. Electrochim. Acta 2016, 214, 307-312.

29. Yin, X.; Chung, H. T.; Martinez, U.; Lin, L.; Artyushkova, K.; Zelenay, P., PGMFree ORR Catalysts Designed by Templating PANI-Type Polymers Containing Functional Groups with High Affinity to Iron. J. Electrochem. Soc. 2019, 166, F3240-F3245.

30. Paulus, U. A.; Schmidt, T. J.; Gasteiger, H. A.; Behm, R. J. Oxygen Reduction on a High-Surface Area Pt/Vulcan Carbon Catalyst: a Thin-Film Rotating Ring-Disk Electrode Study. J. Electroanal. Chem. 2001, 495, 134-145.

31. Kangasniemi, K. H.; Condit, D. A.; Jarvi, T. D. Characterization of Vulcan Electrochemically Oxidized under Simulated PEM Fuel Cell Conditions. J. Electrochem. Soc. 2004, 151, E125-E132.

32. Hsieh, C. T.; Teng, H. Influence of Oxygen Treatment on Electric Double-Layer Capacitance of Activated Carbon Fabrics. Carbon 2002, 40, 667-674.

33. Perez-Rodriguez, S.; Pastor, E.; Lazaro, M. J. Electrochemical Behavior of the Carbon Black Vulcan XC-72R: Influence of the Surface Chemistry. Int. J. Hydrog. Energy 2018, 43, 7911-7922.

34. O’Hayre, R.; Cha, S.-W.; Colella, W.; Prinz, F. B. Fuel Cell Reaction Kinetics. In 
Fuel Cell Fundamentals, 3rd ed.; John Wiley \& Sons, 2016; pp 77-116.

35. Bratsch, S. G. Standard Electrode Potentials and Temperature Coefficients in Water at 298.15 K. J. Phys. Chem. Ref. Data 1989, 18, 1-21.

36. Osmieri, L.; Ahluwalia, R. K.; Wang, X.; Chung, H. T.; Yin, X.; Kropf, A. J.; Park, J.; Cullen, D. A.; More, K. L.; Zelenay, P.; Myers, D. J.; Neyerlin, K. C. Elucidation of Fe-N-C Electrocatalyst Active Site Functionality via in-Situ X-ray Absorption and Operando Determination of Oxygen Reduction Reaction Kinetics in a PEFC. Appl. Catal. B. 2019, 257, 117929.

37. Hsueh, K. L.; Chin, D. T.; Srinivasan, S. Electrode Kinetics of Oxygen Reduction: A Theoretical and Experimental Analysis of the Rotating Ring-Disc Electrode Method. J . Electroanal. Chem. Interf. Electrochem. 1983, 153, 79-95.

38. Damjanovic, A.; Genshaw, M.; Bockris, J. Distinction between Intermediates Produced in Main and Side Electrodic Reactions. J. Chem. Phys. 1966, 45, 40574059.

39. Osmieri, L.; Wang, H.; Neyerlin, K. C. Impact of Fabrication and Testing Parameters on the Performance of a Polymer Electrolyte Fuel Cell with Platinum Group Metal (PGM)-Free Cathode Catalyst. J. Electrochem. Soc. 2021, 168, 014503. 